\title{
The Effect of Using the Art of Harmony and Synergy with Strategic and Cognitive Dimensions in Improving the Methods of Storming Competitors' Strategies
}

\author{
Hani Fadhil Jumaah Al-Shawi \\ Correspondence: Hani Fadhil Jumaah Al-Shawi, business Administration department, Shatt Al-Arab University college, \\ Basra, Iraq.
}

Received: March 23, 2021

doi:10.11114/bms.v7i2.5222

\author{
Accepted: April 6, $2021 \quad$ Online Published: April 25, 2021 \\ URL: https://doi.org/10.11114/bms.v7i2.5222
}

\begin{abstract}
When I start talking about clarifying and explaining what distinguishes between the cognitive, social and performance capabilities of the leader, I must analyze the characteristics of leadership and management related to their perceptions of work activities represented in solving technical problems that arise in the field of administrative work by creating a style of harmony and coping, and the effect of the characteristics of his nature and the reflection of their upbringing on How to create an appropriate climate to contain the emergency situations that hinder the functional and production processes and try to find out whether they have the capabilities that direct it towards (Benchmarking) organizations that develop unique solutions to those situations or not?
\end{abstract}

This study came as an attempt to present explanations and clarifications of the aforementioned by introducing scientific additions to what researchers have gone by, who contributed to drawing a roadmap, but they did not fully seize the opportunity, but rather left it for the coming intellectual generations to put touches on it that approach their reality and their era, which increases questions, ambiguity and challenges. The study aims to develop a (Head, heart, Legs) model for the contemporary managerial psychologist (Finn Havaleshka), which is one of the most important and pioneering scientific contributions in the field of managerial psychology that focuses on explaining the characteristics of individuals at the level of managerial decision-making (administrative and leadership) from By focusing on the cognitive and social aspects, and their impact on performance), let this study be an evolution of this model and an update of what this pioneering scientist started by adding a fourth stage to the model represented by the dimension of (Arms) or arms that defend the successes achieved through their maintenance and preservation. On the one hand, the situation is transferred to the offensive stage by expanding the area of success by using offensive strategies that invade the labor market, as it is said that the best defense is attack. The study was divided into three axes:

The first axis focused on presenting the methodological aspect of the research, while the second focused on the available theorizing and the third covered the conclusions.

Keywords: Harmony, Defensive Capabilities, Focused Leadership, Strategic Capabilities, Cognitive and Social Capabilities

\section{The Methodological Framework for Research}

\subsection{The Study Problem and Its Importance}

The problem of the study is the deficiency and deficiency in the model presented by Finn Havaleshka called (Head, Heart, Legs) as it has the ingredients for success but does not have the ingredients for maintaining success.

The head in the model means the cognitive abilities associated with the skills related to the (administrative) characteristics that Makes the responsible or decision maker in the organization aware of the aspects of successfully managing his organization by making successful decisions that lead to achieving the goals of the organization as for the core.

It is related to the social capabilities related to the skills related to the characteristics (leadership) that enable the decision maker to influence his subordinates in a way that pushes them towards achieving the goals of the organization, and the legs (Legs) are related to the performance resulting from the interaction of the two sets of the mentioned characteristics, but the model neglected how to maintain success, the goals achieved are As a result of concerted efforts that cleverly blended human, material, financial, and information resources and placed them in the right direction to ensure the 
achievement of the goals of the organization, and it is illogical to leave these results in the blowing of the atmosphere predicted by the stormy organizational climate that surrounds the organization without taking the necessary precautions to ensure its sustainability and preservation.

On it and adopting strategies for developing and improving them, which raises the following question that represents the problem of the study: - (Is it possible to add an ability or a fourth dimension to the (Havaleshka) model represented by the capabilities of maintenance (defense) and improvement (attack)?

\subsection{A Philosophical Introduction to Sustainability and Continuous Improvement}

(Bontis 1998p74) believes that the consistency and sustainability of business and performance consists of three variables (creativity and strategic knowledge, proper handling of competitive opportunities in the environment, strategic adaptation) which are dynamic variables and core capabilities (Barney and Hamel 1991) that lead to the speed of response and fusion between the capabilities of the technical infrastructure represented (Cultural, structural, and kinetic) and strategic requirements of the new industry business environment, as contemporary literature in the field of strategic management has been concerned with the fact of the overlap between strategies Knowledge-based business and capabilities, as many researchers (zack, 2002) and (Surch, 2000) agree, (Katsoulakos \& Rutherford, 2005 based view), as the most important strategic resource in achieving sustainable competitive advantage, it is a rare value.

And according to the knowledge-based view (KBV), competitiveness and sustainability in the business environment are a function of strategic knowledge capabilities, learning capabilities, and new knowledge acquisition(Prahalad and Hamel: 1990).

The strategy for competitive strategies is the formation, creation, investment and application of knowledge However, the most important issue in the success of knowledge management initiatives stands at the level of integration between these initiatives and competitive business strategies. Hence, knowledge has occupied a vital position in the various strategic analysis approaches, starting with the resource-based view(RBV), the industry-based view(IBV), and more recently the knowledge-based view(KBV), as the most important strategic resource in achieving competitive advantage. Sustainable, it is a scarce value and is not subject to imitation or transfer. According to the knowledge-based view (KBV), competitiveness and sustainability in the business environment are a function of the strategic knowledge, learning and acquisition capabilities of new knowledge. It is the most important source for raising and activating the business ability to create and add value. ( Jeffrey and Caron: p230)

It becomes clear that the strategic purpose of competitive strategies is the formation, creation, investment and application of knowledge.

(Zack 2000) emphasized this argument by saying that business strategies should reflect the role of knowledge in helping the business to compete (Helping the business to compete).

Knowledge-based capabilities(KBC) are factors that enable and support business organizations to achieve adaptation and strategic integration with the requirements of the competitive environment. Opinion (zack 2001).

The strategic analysis of knowledge-based capabilities $(\mathrm{KBC})$ contributes to enabling business organizations to define the role of knowledge content and processes in enhancing competitiveness and sustainability (Business Sustainability and Competitiveness).

- Achieving sustainability and competitiveness requires business organizations to raise the knowledge-based capabilities (KBC)related to the formation of strategic knowledge that enable them to strategically position in their target markets.

This, in turn, requires the development and improvement of the Absorption Capacity, i.e. The ability to acquire new knowledge and localize previous knowledge to form, create, represent and exploit new knowledge, and in fact the strategic business capabilities (including knowledge-based capabilities (KBC)) can be developed within the framework of two phases:

- The first phase:- the synthesis or synthesis phase

-The second phase:-- (combination and the exchange phase).

Intellectual capital that reflects the overall function of current and potential synergistic capabilities that are derived from relational networks of business. 
- The development and building of knowledge-based strategic capabilities (KBSC) requires, first of all, the modernization of the infrastructure in three strategic areas:

1. technical

2. structural

3. and cultural infrastructure

- The structural structures refer to the mechanisms of integration and coordination between the activities and activities of business, while the cultural structures focus on creating climates supportive of improving performance and the culture of creativity, while the technical structures mean the pattern of interconnections and assistive technical mechanisms.

- The elevation and improvement of the infrastructure capabilities must be in the context of re-engineering knowledge management processes (Knowledge Re-engineering) represented in creating, creating, transforming, coding, disseminating and storing knowledge, which are processes that enable business organizations to acquire, explore and transfer new knowledge and invest current knowledge efficiently According to Grant's perspective, knowledge integration is a function of the interaction of three factors, which are the efficiency of cognitive integration, the scope of cognitive integration, and the flexibility of cognitive integration, as the frequency of knowledge processes is an important determinant of the competence of cognitive integration.( Gold: (2001) :p189)

One of the exceptions that in turn determines the scope of integration, while the flexibility of knowledge integration refers to the ability of business to re-synthesize (synthesize) knowledge.

- I summarize from the foregoing that the success of Strategic Knowledge Management(SKM) depends on the efficiency of business organizations in developing and building two types of strategic capabilities:-

First: Infrastructure Knowledge capabilities(IKC): Represented by the technical, structural and cultural infrastructures.

The second: the capabilities of knowledge processes, represented by the processes of acquiring, transferring, applying and protecting knowledge.

Business organizations usually seek to launch effective knowledge management initiatives in order to achieve a balance between the knowledge content (implicit or explicit), knowledge processes and the knowledge infrastructure.

- The results of strategic cohesion between infrastructure, knowledge content and processes is the most important determinant for building and strengthening competitiveness and sustainability.

Strategic knowledge management (SKM) is not a single project in itself, but rather a complex combination of inputs.

The codification strategy requires employing capabilities A high-level technology for acquiring, storing and transferring explicit knowledge, which in turn requires the adoption of a strategy for integration and dissemination of knowledge between existing knowledge symbols to create new knowledge.

Likewise, implicit knowledge capabilities focus on developing common contents of knowledge by employing advanced technologies in the field of communication and information technology.

Infrastructure capabilities to develop and integrate tacit knowledge through dissemination and transfer mechanisms.

- Technical capabilities of knowledge represent the most important dimension in the transfer and dissemination of knowledge, through its effective contribution to creating knowledge integration. Perhaps the most important of these capabilities are (business intelligence, cooperation and learning mechanisms, knowledge maps, and competitive intelligence).

As for the structural capabilities, they are necessary to support and support the technical capabilities of the business, and although it aims to achieve rationality and orderliness in performance, it may create unintended consequences in hindering relational networks for the spread and integration of knowledge.

As the optimization of the sharing and transfer of knowledge between the components of the cognitive system requires the development of organic structures with high flexibility to support networks of exchange or knowledge cooperation along the supply chain.

- Finally, cultural capabilities are considered the most important barrier to the success of knowledge management initiatives.

The value system is an important determinant of creativity, creation of new ideas, sharing of tacit knowledge or transforming tacit knowledge into explicit or explicit knowledge.

As indicated in the literature, the most important component of the cultural system of business organizations is the clarity of the strategic vision and the strategic presentation (Strategic Intent \& Vision). 
The clear strategic vision and shared values contribute to strengthening and building appropriate climates for the growth and prosperity of knowledge.

Trust and openness are positive factors to support creative and cognitive behavior in business organizations.

Ahead of operation capabilities (Process Capabilities) they are techniques of translating and employing knowledge into competitive advantages, which are represented in (processes of acquiring, integrating and transferring knowledge) or it is the processes of formation, transfer and use of knowledge, regardless of the techniques of knowledge operations, it means in fact the enabler factors to translate and transfer the accumulated knowledge to sustainable competitive advantages, as it is the dynamic framework for the creativity of knowledge assets. (Caruccl D. et al: 2004).

The brief discussion of the strategic capabilities of knowledge confirmed that activating and maintaining knowledge management initiatives can be framed around two types of strategic capabilities: knowledge infrastructure capabilities (KIC)and knowledge processes capabilities(KPC), both of which contribute to strengthening the role of knowledge in achieving business competitiveness and sustainability

\subsection{Knowledge Management \& Business Competitiveness}

The issue of overlap between Knowledge-Based Capabilities and Sustainable Business Competiveness is considered a hot research issue in the literature of strategic management, despite the ambiguity surrounding the concept of sustainable business competitiveness as a contemporary concept in the literature.( Helen: 2000: p34)

It has been the focus of attention of the various strategic analysis approaches.

While the Industry-Based View(IBV) justified business competitiveness in terms of the dynamism of the competitive environment and the business ability to build competitive leading positions in the industry (Porter\& Black: 2000),

the resource-based view(RBV) (emphasized View) that building distinctive resources and capabilities (Barney and Hamel 2013) is the most important pathway to achieving competitiveness and sustainability.

More recently, the Knowledge-Based Perspective(KBP) explains business competitiveness in terms of its ability to explore and invest knowledge (Knowledge Exploration \& Exploitation) and employ it in achieving value added.

The knowledge-based view(KBV) is a valuable extension of the strategic resource and capabilities based view(CBV), and it is an inevitable result of the accelerating transformations from industrial economies to the knowledge economy, as it is clear that the most important strategic source for achieving competitiveness and sustainability in the contemporary business environment is the ability to create and invest knowledge.

The strategic knowledge-based capabilities(SKBC) are the valuables, non-substitutable (Inimitable), or (NonSubstitutable) and Distinctive. they are the most important in explaining the variance or variance in business competitiveness.

Knowledge-based strategic capabilities(KBSC), whether they are Process Capabilities or Infrastructural Capabilities, are those systems and processes that organizations seek to build in order to raise, activate and create sustainable advantage within the framework of a knowledge-based view( KBV) (Barney (2000): p18)

(Zack:2001) also indicated that knowledge is the basis for excellence and creativity, and both contribute to creating new ways to integrate existing resources or develop new capabilities, which in turn means improving sources of sustainable competitiveness by raising the capabilities of adaptation, flexibility and response to competitive opportunities.

(Claudia) believes that competitiveness is the open variable for the success of organizations in the long term, as it drives approximately (70-80\%) of business competitiveness in the knowledge economy, and many researchers have agreed that knowledge management is the most important source of competitiveness and sustainability for twenty-first century organizations.

\section{A Philosophical Discussion of the Problematic Relationship Between the Variables of the Havaleshka Model}

The organizational psychologist (Finn Havaleshka) constructed an individual psychological model that presents and is based on three capabilities of the individual that he uses to fulfill work requirements, namely: - (Al-Ghalabi and Idris, 2007, p. 449).

First: - The manager's cognitive capabilities

(Management characteristics) associated with cognitive Competencies

Second: - The leader's social (behavioral) or leadership capabilities

Third: - Performance Competencies

The researcher believes that there is a hypothetical necessity to include or develop a fourth capacity for the Finn Havaleschka model represented by the capabilities of sustainability and continuous improvement. 
It was called the head and deals with the first, the heart deals with the second, and the stems deal with the third

The head is about direction and problem solving, the heart is about communication and communication, the stems are about performance and institutional decisions.

I believe that the two arms are compatible with the fourth capabilities that I propose to add to the model so that the whole picture is structurally and theoretically related to defense, control and facing external environmental challenges.

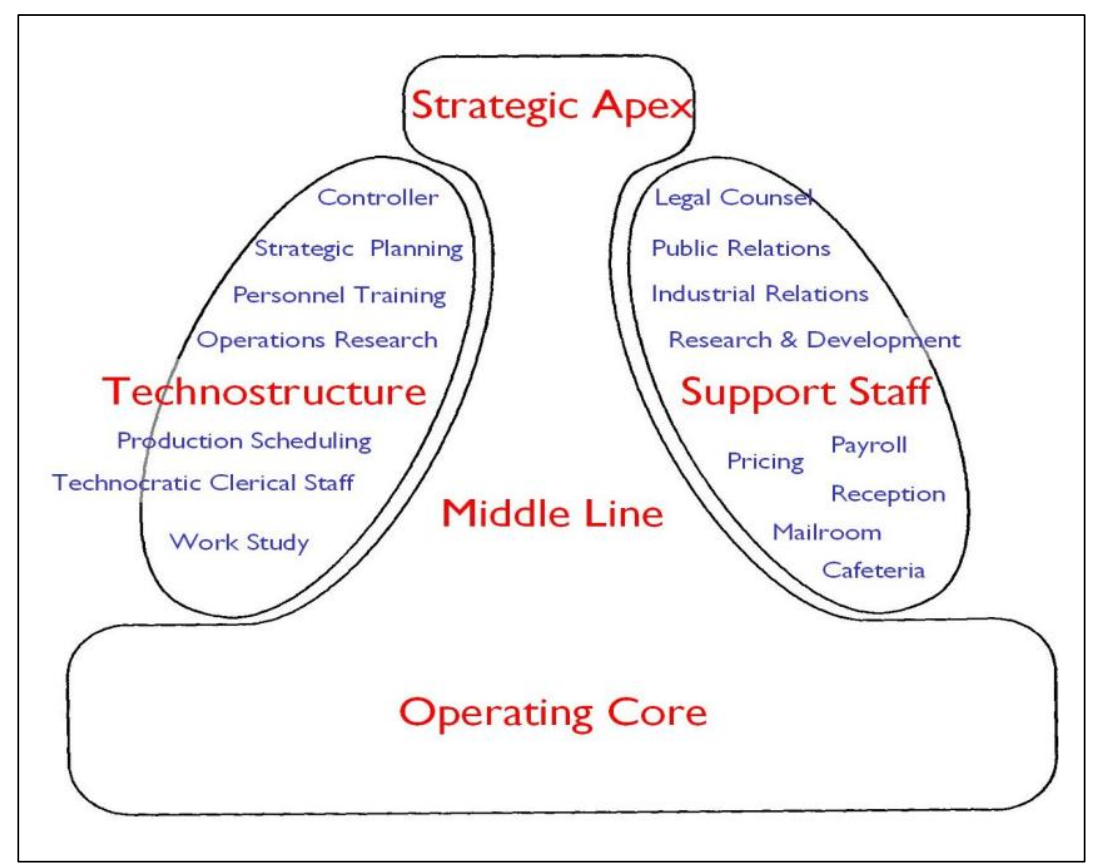

Figure 1. The proposed addition is an arm with the four capabilities of the Havalska model

Source: Henry Mintzberg In his classic book, The Nature of Managerial Work. 1973 prentice hall,1980

And I believe that the two arms are compatible with the fourth capabilities that I propose to add to the model so that the picture is structurally and theoretically complete and related to defense, control and facing external environmental challenges and the possibility of using the attack and construction. According (Mintzberg ,1973: P167). In his classic book, The Nature of Managerial Work.

\section{Is to be the rich picture}

I hope that this addition is not a mere gossip that does not deserve attention.

Because it will bring us support for the idea because this world is a volatile world and not a frozen world.

They should be flexible and accept renewal, that they are not one-sided, and that they do not waste most of their time stealing the views of others.

And I continue our dialogue on the topic, as the head builds and innovates ideas while the heart in the process of persuading others, and the legs achieve the desired results, and because the behavior of individuals, social systems and culture have a mutual influence on each other, Havaleschka developed the three capabilities into a measuring tool for organizational culture that stems from Each of the capabilities has two main dimensions, (Finn Havaleschka and Gert HN. Laursen1993: p18) 
As the first head dimension represents

the direction of the business organization and the solution to the problems facing the organization, and problem solving represents the natural end of the innovative thinking of the manager and the business organization in which the individuals have a high degree of freedom to choose and create new ideas, and in the other dimension of the head there is a traditional problem-solving culture, Which focus on traditional methods, the most important of which are:

First: - The method of collective solution in solving problems

This method is preferred because of its advantages:

1. Diversity of ideas.

2. Multiple sources of information.

3. Less bias since it negates personal reasons.

4. High commitment to performance.

5. Choose the best solutions in a consensual manner.

6. Participation of all administrative levels in the solution.

However, each method has its drawbacks and the disadvantages of the collective approach:

A. Neglecting to register ideas.

B. Excessive competition.

C. To keep up and accompany due to the position of one of the participants in the solution, such as the general manager, for example.

D. The lack of an objective orientation.

E. Temporal and spatial restrictions.

F. Controlling the thinking phenomenon of the president or manager.

The solution to this phenomenon, as he sees (Al-Fahdawi, 2004, p. 35) is to follow the approach or model of leadership that is transformed from one person to another.

Second: - The individual approach to problem solving

It is the method that the majority of managers rely on in making individual decisions, which can be described in two ways.

-The first is the rational or logical approach that states issues that managers must follow in order to try to make decisions.

-And the second approach is the approach of restricted rationality, which is the perspective that helps managers how to make decisions under restrictions or severe limitations in terms of time and resources, and the first entry is the best approach that managers can turn towards, but without reaching it at all (Daft: 2001\& 2000: 342).

\section{3. conclusions}

\section{1 conclusion}

What the researcher found

The researcher believe that solutions can be found in the following ways:

1. Changing the organizational structure and in line with the new situation solution.

2. Change the work and its management in a manner consistent with the proposed change to overcome obstacles.(peter1983: p234)

3. Changing the technical means used to complete the work.

4. Changing the people or persons who caused the lingering problems, if required, even by coercion. As for the dimension of the heart, it represents the social characteristic, as it defines the quality and means of cooperation in the two dimensions of communication and communication, and the collective participation process, as the after contact and communication is supposed to be transparent and open between individuals and managers. Dual and learning from past mistakes. 


\subsection{The Last Conclusion}

1. Beliefs are a complex factor that the individual does not allow to criticize, object to, or diminish his importance, and because of the bifurcation and breadth of those beliefs, the individual who embraces them becomes obligated to make an appropriate reaction to any idea or opinion contrary to some of those beliefs, and he feels a strong psychological bond that attracts him towards those who share it. Those beliefs, but if it is discovered that another party disapproves of something of his beliefs, the feeling of discomfort is the primary result, which may develop to a high degree of danger because it will be reflected on his behavior towards that individual or group(Johnson\& Johnson 2012, p:34).

2. Values are rules of behavior that are transmitted between individuals who belong to a specific group through social processes and factors (Stangor C 2014: p 204) And (.Crump, S. A., Hamilto: 2010: P:1215).

3. The values of the individual are closely related to his biological, psychological and social nature, and what he carries in terms of values is an amalgamation of the instinctive and learned motive, so researchers have divided values into six main groups: theoretical, economic, aesthetic, social, political and religious values ( Dagher,and Harouch 2000: 269) .

4. And it is noticed that these groups are closely related to human nature, which means that their influence falls on various classes of society, including managers, even if the degree of influence is different.(William and others: 200; p312)

5. The third dimension represents the stems of the organization's decisions and performance culture, and here a distinction is made between performance and decisions (David 1999, p:373) presented his views on performance by structuring them in five main areas related to the following:

\section{A. Goals}

B. Strategies and plans developed to achieve these goals.

C. An organizational structure to encourage performance.

D. Reverse information sessions.

E. Conducting continuous improvement processes on those processes to manage organizational performance and identify fruitful research areas to continue doing so.

6. Symbols indicate what the individual sees as a source of pride for him, such as the clan, family, place and nature of work, the city in which he was born, and distinctive social characteristics such as honoring the guest and others, as the individual works to preserve this and not allow others to detract from it, and the individual working in the organization and its director or leader is not free of attachment to So and stick to it and reverse it in the work environment. (Daniels: 2001: p45)

Usually the symbols form a strong impetus for the individual to do something or vice versa, but that work remains dependent on the nature of the symbol itself, which means that there are at least two types of symbols: the positive symbols that positively affect the organization, and the symbols that negatively affect the organization.

7. The researcher 'agreement on many of these variables (such as demographic variables, beliefs, values and customs) is due to the existence of common factors between societies and related to human nature in general.(Hogg: 2003: 474)

8. As for the difference of researcher in some of these variables, it is due to the privacy that each society enjoys and that distinguishes it from other societies. Social capabilities (heart)

The social culture environment consists of several variables, researchers sometimes differ in their nature in addition to their number, and perhaps the reason for this does not mean that there is no agreement on them, but rather because the nature of societies differs. Each society has its own cultural and social characteristics. (Ivancevich\&, 2003, p358)

\section{References}

Al-Fahdawi, \& Fahmy, K. (2004). Administration in Islam. House of the March for Publishing, Second Edition, Amman, Jordan, 2004.

Al-Ghalbi, Taher, M. M., Idris, \& Wael, M. S. (2007). Strategic Management, an Integrated Methodological Perspective. Wael Publishing House, First Edition, Amman, Jordan. 2007.

Aubrey, C., \& Daniels. (2001). Other Pepels Habits. how to use positive reinforcement to bring out the best in people around you, McGraw-hill.

Barney, \& Hamel. (1991). The Core Competence of the Corporation. Publishers, USA.

Barney, \& Hamel. (2013). The Core Competence of the Corporation. Publishers, USA.

Barney, J. B. (2000). Firm resources and competitive advantage. Advances, Journal of International Marketing, 18, 1-19.

Bontis, N. (1998). Intellectual capital: An exploratory study that develops measures and models. Management Decision, 
36(2), 63-76. https://doi.org/10.1108/00251749810204142

Caruccl, D. (2004). The knowledge value chain: How Intellectual capital Imaets on Business Performance. Retrieved from http://www.indercienceenterprise.com

Crump, S. A., Hamilton, D. L., Sherman, S. J., Lickel, B., \& Thakkar, V. (2010). Group entitativity and similarity: Their differing patterns in perceptions of groups. European Journal of Social Psychology, 40(7), 1212-1230. https://doi.org/10.1002/ejsp.716

Daft, R. L. (2000). Managenet. Harcourt College Publishers, USA, 2000.

Dagher, M., \& Saleh, H. (2000). Organization Theory and Organizational Behavior. Directorate of Dar Al-Kutub for Printing and Publishing, Baghdad 2000.

David, O. (1999). Management Accounting Research. https://doi.org/10.1006/mare.1999.0115

Deresky, H. (2000). Management. Prentice Hall, USA, 2000.

Finn, H., \& Gert HN, L. (1993). Human Resource Management \& Development. A concept from GARUDA Research Institute. (C) Finn Havaleschka, Garuda Europe. This booklet and the models and methods described in it, are protected according to the law of copyright.

Goetsch. D. L., \& Davis, S. B. (1997). Introduction to Total Quality. Prentice Hall, USA, 1997.

Gold. (2001). Strategic Knowledge Management. Journal of Management Information Systems, 8, 182-194.

Harrison, Jeffrey, \& John, C. (1998). Foundation of Strategic Management. Ohio, USA, 1998.

Henry, M. (1980). The Nature of Managerial Work. Prentice Hall, 1980.

Hogg, M. A. (2003). Social identity. In M. R. Leary \& J. P. Tangney (Eds.). Handbook of self and identity, 462-479. New York, NY: Guilford Press.

John, M. I., \& Michael, J. M. (1993). Organization Behavior and Management.

John, M. I., Peter, L., \& Steven, J. S. (2003). With Philip B.crosby. Management Quality and Competitiveness. Second Edition, Irwin, USA. 2003.

Johnson, D. W., \& Johnson, F. P. (2012). Joining Together - Group Theory and Group Skills (11th ed). Boston: Allyn and Bacon.

Katsoulakos, \& Rutherford. (2005). An introduction to knowledge oriented strategy (KOS) and strategic knowledge management capabilities. Retrieved from www.kbos.inte.com

Nickels, W. C., \& Mchuch, J., \& Mchuch, S. (2002). Unedrstanding Business, $6^{\text {th }}$, McGrow, USA, 2002.

Peter, J. T. (1983). Proceedings of Themeat Industry. Research Conference, Amerecan Meate Institute, Chicago.illinois, 1983.

Porter, L. W., \& Black, J. S. (2000). Management. Prentice Hall, USA.

Prahalad, \& Hamel. (1990). Core-Competencies as the Drivers of Corporate. Prentice Hall, USA,

Ricard, 1. D. (2001). Organization Theory and Design. South Western College Publishing, USA.

Stam, C. (2007). Knowledge Productivity. Phd Dissertation University Of Tent, Netherlands.

Stangor, C. (2014). Understanding Social Groups, 204-210.

Zack, M. (2001). Strategic Pretext for Knowledge Management. Retrieved from http:www.northeastren.com

\section{Copyrights}

Copyright for this article is retained by the author(s), with first publication rights granted to the journal.

This is an open-access article distributed under the terms and conditions of the Creative Commons Attribution license which permits unrestricted use, distribution, and reproduction in any medium, provided the original work is properly cited. 